\title{
The Residential DC power Distribution with Multi-Input Single-Control Systems
}

\author{
M.Karuppiah ${ }^{\# 1}$
}

\author{
K.Karthikumar ${ }^{\# 2}$ \\ Assistant Professor \\ Department of Electrical and Electronics Engineering \\ Vel Tech (owned by RS trust) Engineering College \\ Avadi, Chennai-62, Tamilnadu, India.
}

\author{
A.Arunbalaj ${ }^{\# 3}$
}

\begin{abstract}
Environmentally friendly technologies such as photovoltaic's and fuel cells are DC sources. In the current power infrastructure, this necessitates converting the power supplied by these devices into AC for transmission and distribution which adds losses and complexity. Now-a-days, due to power failure, there is a great used for UPS systems in our homes or in workplaces and also the amount of DC loads in our buildings is ever-increasing with computers, televisions, and other electronics entering our workplaces. This forces another conversion of the $\mathrm{AC}$ power to $\mathrm{DC}$, adding further low power ratings, losses and complexity. Due to low power rating of the system, it is very important to reduce number of converter stages and use the generated energy efficiently. Therefore, instead of using different dedicated converters from various uni-directional renewable sources, this paper proposes a single stage boost converter with multiple inputs that can efficiently decimate generated energy. The proposed converter works under various operating modes which are discussed in this paper. This paper proposes the use of a DC distribution system.
\end{abstract}

Keywords-Dc distribution line, multi input single controller, maximum power point muti port

\section{INTRODUCTION}

Increasing demand and environmental concerns have forced engineers to focus on designing power systems with both high efficiency and environmentally friendly. The natural resources such as fossil fuels while reducing the human impact on the environment through a reduction in pollution. The most well-known environmentally friendly is photovoltaic's and wind turbines [1]. Although fuel cells are not considered an environmental friendly, but fuel cells have low emissions compared to other forms of energy. Unfortunately, the established power system infrastructures are based on alternating current (AC) while two of the leading environmentally friendly energies, fuel cells and photovoltaics, produce direct current (DC). Currently, power system infrastructures that wish to incorporate fuel cells and photovoltaics must first convert the DC power produced by these energy sources to AC [2]. This adds complexity and reduces efficiency of the power system due to the need of a power converter. Furthermore, a due to power failure, there is a great used for UPS systems in our homes or in workplaces and an increasing number of DC consuming devices such as computers, televisions, and monitors are being incorporated into our buildings. The power supplied to these devices must be converted again from $\mathrm{AC}$ back to DC adding further losses and complexity to the power system. Instead of using multiple converters to convert DC to AC and then AC to DC, the power system could only be based on DC. This would eliminate the need for two sets of converters for each DC load, reducing the cost, complexity, and possibly increasing the efficiency. However, a definitive analysis on a DC distribution system is needed to determine the net benefits of eliminating the converters. In the environmentally friendly energies photovoltaic, wind and fuel cells are having some of the drawbacks, so reduces this drawback using multiple energy source for a distribution this paper, proposes the use of a DC distribution system using multi input single control system.

\section{PROBLEM BACKGROUND}

Since the development of electricity, AC has been describing as the better choice for power transmission and distribution. However, Thomas Edison one of the founders of electricity supported the use of DC. No method at that time existed for boosting and controlling DC voltage at the load, so that transmission of DC power from generation to load resulted in a large amount of losses and voltage variations at the different load locations. To resolve this issue, Westinghouse proposed AC distribution [2]. Tesla showed the practical advantages of alternating current. Transformers made it possible to step up an AC voltage easily, this allowed for efficient transmission of power from one location to another resulting in a complete transformation of the power systems to AC. Although many things have changed since the invention of electricity, AC is still the fundamental power type of our power infrastructure. However, due to the development of power electronics which gives a better utilization of existing transmission corridors with high voltage DC connections. High voltage DC transmission allows more power to be 
transmitted over a long distance with fewer losses compared to an AC transmission. Power electronics makes efficient and accurate control of electrical power possible. Efficient AC to DC, DC to AC and DC to DC conversion technology are now available on the market, where DC to DC conversion is more efficient than $\mathrm{AC}$ to $\mathrm{DC}$ conversion. Power converters and DC energy sources, interest in DC has returned. Several studies have investigated the use of a DC distribution system.

Fig. 1 shows the block diagram of a obtainable system. An input solar source (Vp) is interfaced to a DC distribution bus (Vd) using a DC to DC converter. It uses a DC based distribution with various loads connected to it through dedicated point-of-load. The idea is basically inspired from computer power system. The renewable power sources are generally DC. Due to the intermittent nature of renewable sources, even though the generated power is AC or DC (e.g., solar power is $\mathrm{DC}$ and wind power is $\mathrm{AC}$ ), they are converted to a $\mathrm{DC}$ and use it further processing. Another factor that improves efficiency is: more the distribution voltage $(\mathrm{Vd})$ less is the current for the same power level. Therefore, a boost stage between the solar panel and distribution bus is advantageous [3]. The choice of voltage level is dependent on the power level of the distribution and available area for renewable installation. Never the less, in most implementations, a boost converter is used to interface the source with the DC bus.

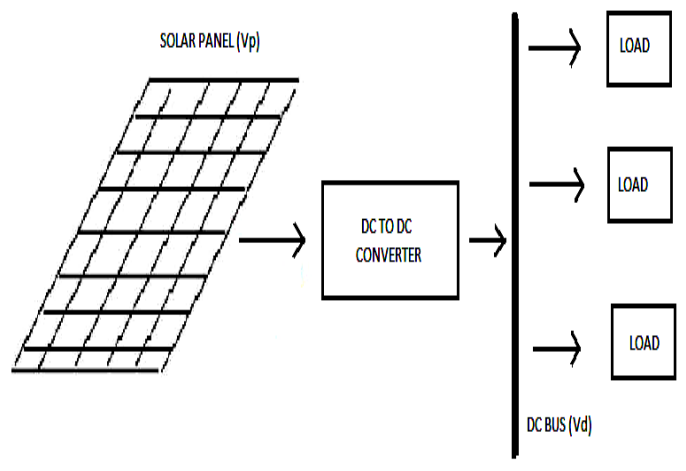

Fig. 1. Existing system block diagram

This is because, from MPPT point of view, in a smaller installation, the solar panels (generally, with open circuit voltage of $12-36 \mathrm{~V}$ ) are not preferred to be connected in series. They are paralleled as this arrangement has less impact on power generation. So reduce this power generation using conventional system of a single stage boost converter with multiple inputs that can efficiently decimate generated energy.

\section{PROPOSED SYSTEM}

Future DC based system will have various sources interfaced to the DC-distribution bus as shown in Fig. 2. Unidirectional Renewable Sources are interfaced directly to the converter from which power is supplied to the distribution bus. When bidirectional sources are used it is directly interfaced to the distribution bus through a dedicated converter. Renewable Sources have varied characteristics, e.g., a solar array is a current source and a fuel cell is a voltage source. In order to interface all these sources to a single domestic supply grid, a converter has to be interfaced between the respective nodes. The converter takes care of the regulation and protection which arises because of the interfacing a multiport converter is described which uses multiple boost converters with common output as interfaces between various sources and the DC bus. A multi-input series output concept is used to realize this interface which works at ZVS. Most of the researches have addressed the multi-source power utilization problem by using individually controlled converters. That means, the source and DC bus have a dedicated converter between them. This option is quite good for higher power installations. However, in a DC bus where the power generation is limited and the sources have limited output, these options may not be the most efficient ones as more converters will degrade efficiency and reliability. This paper looks at an alternate circuit to realize a power electronic interface for DC bus, with multiple unidirectional input sources and a single output. The converter structure is realized using a single master control with multiple sources of relatively smaller power rating. The output of the converter is directly connected to a distribution network an additional stages as well as MPPT control.

The organization of paper is as follows Section II gives a problem background and existing system. Section III describes general topology of proposed Converter. Section IV and V describes the possible modes of operation a multi stage converter system with different input sources. Section VI describes the master source control. In Section VII experimental verification of proposed topology is done. Section VII presents conclusion of this paper.

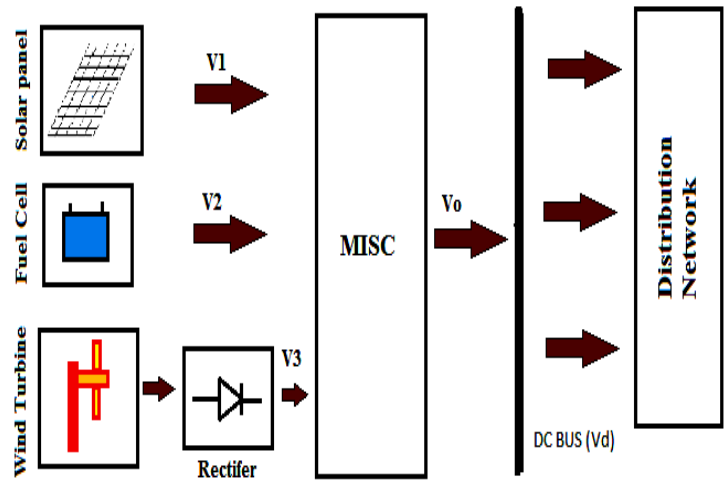

Fig. 2. The Proposed system block diagram 


\section{MULTI-INPUT SINGLE CONTROL (MISC) TOPOLOGY}

The overall topology is derived from boost Converter as shown in Fig. 3. There is a Master source $S_{1}$ this source can be voltage or current source and slave sources $S_{2}$ to $S_{n}$ are interfaced to the drain of the control switch through dedicated inductors. The converter topology is referred to as Multi Input Single Control due to the fact that the master source is always in control of the duty [4]. The Master Source $S_{1}$ fixes the duty cycle of switch $\mathrm{M}_{1}$ based on the MPP operating point of the input source, if input is a solar panel. In this case the current is used to supply the loads connected to this bus. In case of a voltage source, the output current of the boost can be controlled. The loads are connected to DC bus directly. As the converter topology is based on boost converter output voltage is always greater than input voltage for the operation of the converter.

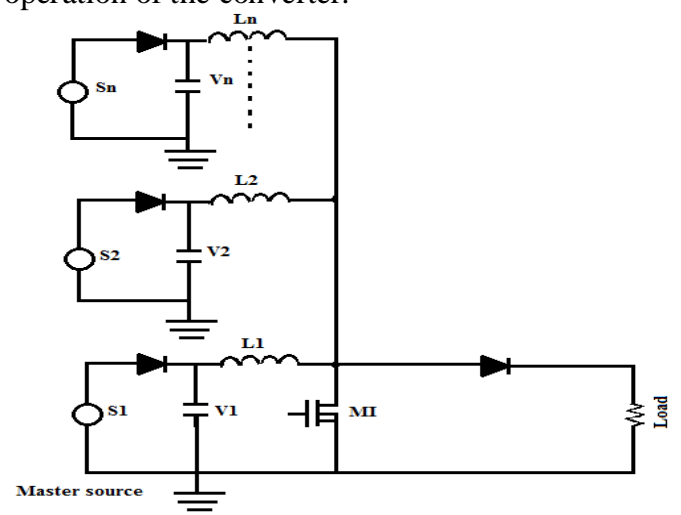

Fig. 3. Multi input boost converter

Depending upon the characteristics of the sources connected to the converter it can be classified either as a voltage or a current source.

It is important to note that all the common renewable sources are unidirectional in nature and should be interfaced with a diode. When a current source is interfaced to the converter, a capacitor is used at the input terminal as can be seen from Fig. 3. This capacitor is required to meet the ripple requirements of the converter input current. When the source has a voltage source property, an input capacitor is avoided as it will invariably force the capacitor voltage to become equal to the master source terminal voltage due to duty constraint.

\section{MODES OF OPERATION}

The different modes of operation of MISC converter is as outlined in Table I. All the modes given in Fig. 4 are valid if the basic constraint of output voltage being greater than input voltage is satisfied. Note that the output of the converter is connected to DC bus. The resistive load represents the load on the DC bus. All the operating modes explained below are very much dependent on the design of input inductor. This design philosophy will be covered in the next section.
Table. I. Modes of Operation

\begin{tabular}{|c|l|l|}
\hline \multirow{2}{*}{ Mode } & \multicolumn{2}{|c|}{ Modes of Operation } \\
\cline { 2 - 3 } & Master Source & Slave source \\
\hline I & Current Source & Voltage Source \\
\hline II & Current Source & Current Source \\
\hline III & Voltage Source & Voltage Source \\
\hline IV & Voltage Source & Current Source \\
\hline
\end{tabular}

MODE I: CURRENT SOURCE AND VOLTAGE SOURCE

As shown in Fig. 4, when a current source is the master source and voltage source acts as a slave source there are two operating scenarios possible which is explained below as two sub-modes [2]. The duty ratio for these modes is fixed by the current source.

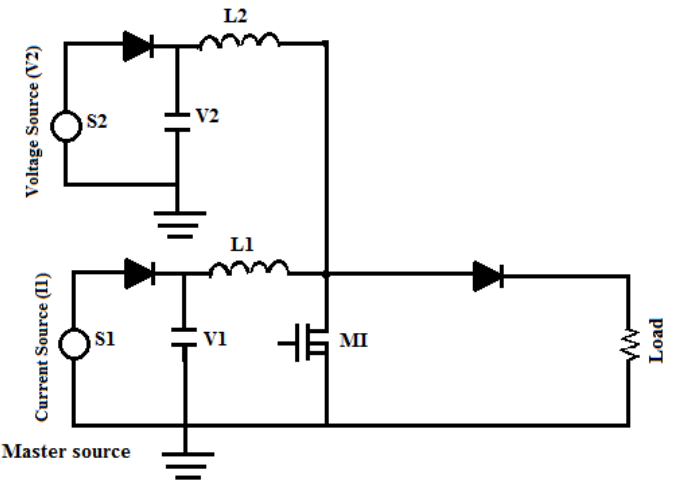

Fig. 4. Current and voltage source inputs

1) Sub-Mode I-A: VI > V2:

When the input voltage of the master source is greater than that of the slave sources there will be 3 operating intervals for multi input boost converter, for a properly designed inductor, the current through the inductor $\left(\mathrm{L}_{1}\right)$ of master source will be in current source. Therefore, for a similar or smaller value of inductor $\left(\mathrm{L}_{2}\right)$, the current from slave source will be in voltage source. Assuming the $\mathrm{L}_{2}$ to be smaller is reasonable as the power rating of the slave source is not high. The inductor Current waveforms $\mathrm{IL}_{1}$ and $\mathrm{IL}_{2}$ are as shown in Fig. 5.

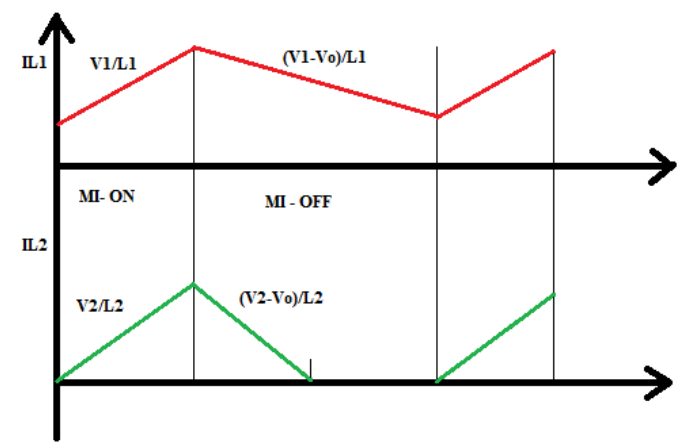

Fig. 5. Inductor current waveforms $\mathrm{IL}_{1}$ and $\mathrm{IL}_{2}$

2) Sub-Mode I-B: VI $\leq$ V2:

When the master source terminal voltage is equal to that of the slave source, both the input 
currents are ideally in constant control mode. However, this may not be possible all the time, as the second source is assumed smaller. This may lead to the second source working under current limit. Similarly, if slave source voltage is larger, for same duty cycle as the master, its current will invariably reach current limit. Therefore, all that can be said about this mode is that, in a practical development, the slave source works under current limit. The inductor current waveform IL2 indicated in Fig. 5 indicates the state of operation before the source current reaches its limit. When the slave source reaches current limit the inductor current waveform depend on the characteristics of source such as type of source, source impedance etc.

\section{MODE II: CURRENT SOURCE AND CURRENT SOURCE}

In this mode both inputs are current source is connected to multi input boost converter. It is shown in Fig. 6. The terminal voltages $V_{1}$ and $V_{2}$ will be forced to become equal by the duty ratio of the switch controlled by master source.

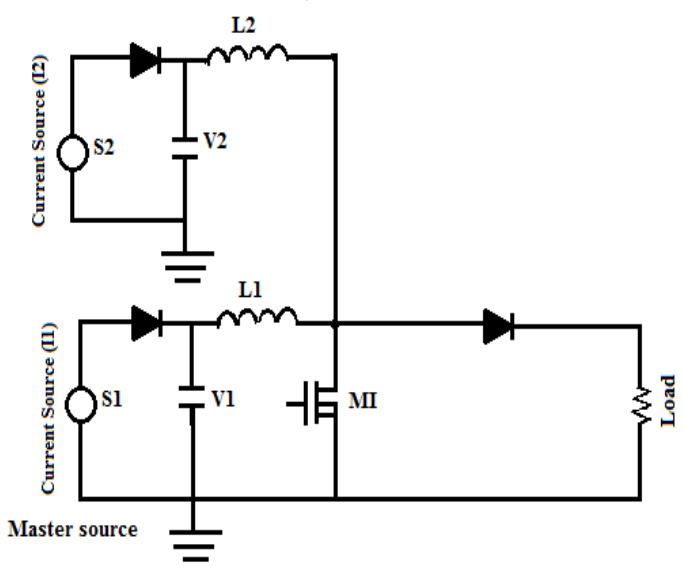

Fig. 6. Current source inputs

For normal operation of MISC converter the inductor current waveforms are as shown in Fig. 7.

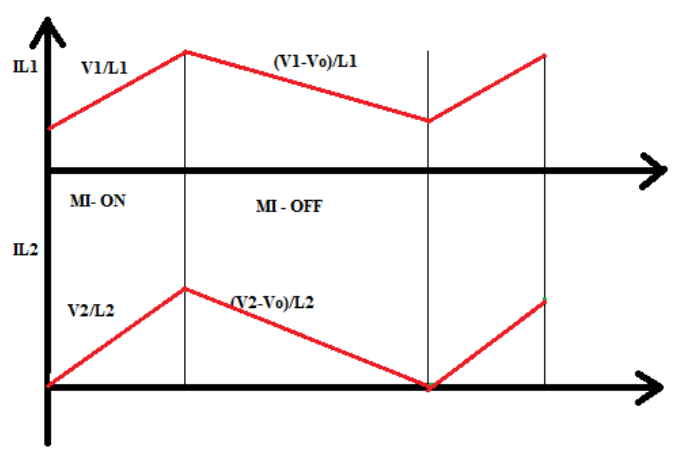

Fig. 6. Inductor current waveforms $\mathrm{IL}_{1}$ and $\mathrm{IL}_{2}$

The normal operation of the converter is valid when input inductors and capacitors are selected properly. Ideally current IL I drawn from the source should be transferred only to the output and therefore this operating development is not efficient. To prevent this mode of operation the proper selection of Inductance and capacitance value is mandatory.

\section{MODE III: VOLTAGE SOURCE AND VOLTAGE SOURCE}

The inputs of MISC converter are connected to voltage sources as shown in Fig.7. In this mode of operation there are two sub-modes possible which are given below. The duty ratio for this mode is fixed by the master source.

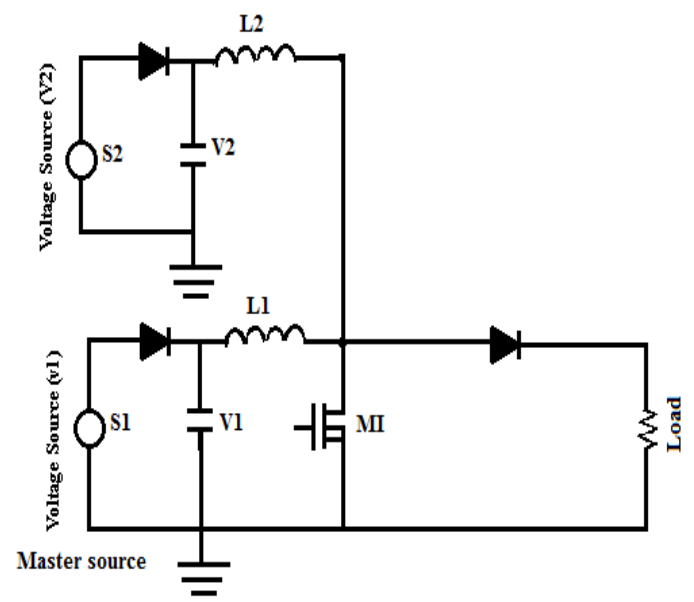

Fig.7. Voltage source inputs

1) Sub-Mode III (A): VI > V2:

When input voltage of master source is greater than the slave source voltage there will be three operating intervals. The slave voltage source will be forced to operate in discontinuous current mode as the gain required is more [5]. As the power generated from the source is not very high, interfacing a separate converter for power extraction is not necessary and discontinuous current mode operation can be used for extraction of the available power. The input current waveform is as shown in Fig. 8.

\section{2) Sub-Mode III (B): VI $\leq$ V2:}

In this sub-mode of operation the input inductor currents I L I and I L2 ideally should operate in continuous current mode. As the duty ratio is fixed by master source, when input voltage of master source is less than or equal to the slave source voltage it will have a higher gain than required due to higher duty ratio. Output current from slave source increases till it reaches its current limit which is the equilibrium point of operation for the source [5]. The input inductor IL2 current waveform before the slave source reaches the current limit. When source reaches the current limit the operating waveform will depend of source characteristics such as source type, source impedance etc. 


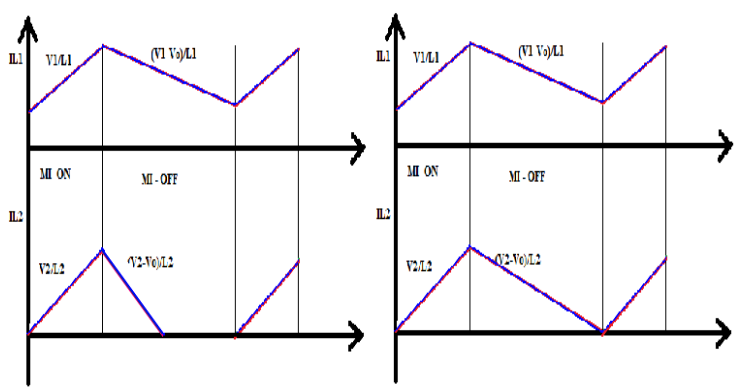

Fig. 8. Inductor current waveforms $\mathrm{IL}_{1}$ and $\mathrm{IL}_{2}$

\section{MODE IV: VOLTAGE SOURCE AND CURRENT SOURCE}

When a voltage source is the master source and a current source acts as a slave as shown in Fig. 9, the duty ratio of switch M1 is controlled by voltage source. The terminal voltage V2 of the current source will be forced to be equal to terminal voltage V1 and the current that can be supplied by the source is drawn from the source. There will be only two operating intervals.

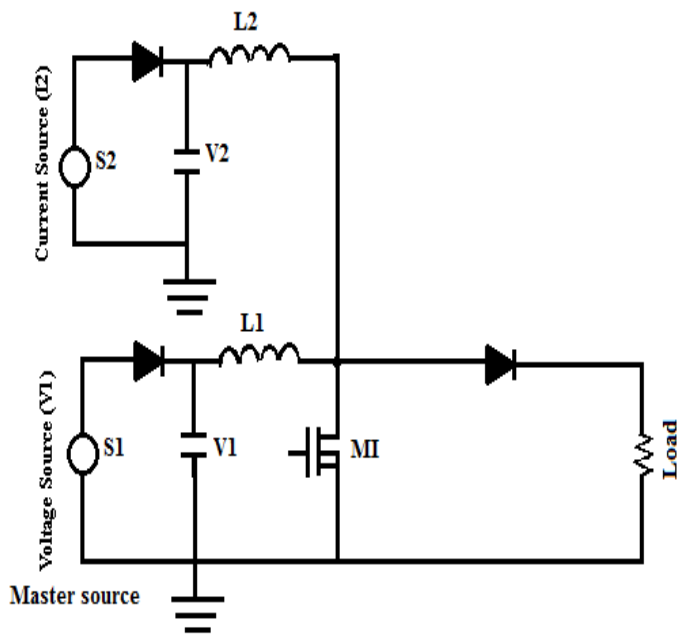

Fig. 9. Voltage and current source inputs

Under Normal operating conditions, when the input inductor and capacitors are selected properly, both the converters work in continuous current mode operation and the input inductor current waveforms are as shown in Fig. 10. Under high ripple operation which is caused when low value of inductance is selected and proper value of capacitance is not used to maintain the ripple the input current waveforms. This mode of operation is not preferred as the there is a negative portion of current which indicates the charging of the slave source input capacitor by master source which reduces the amount of current flowing to the output [6].

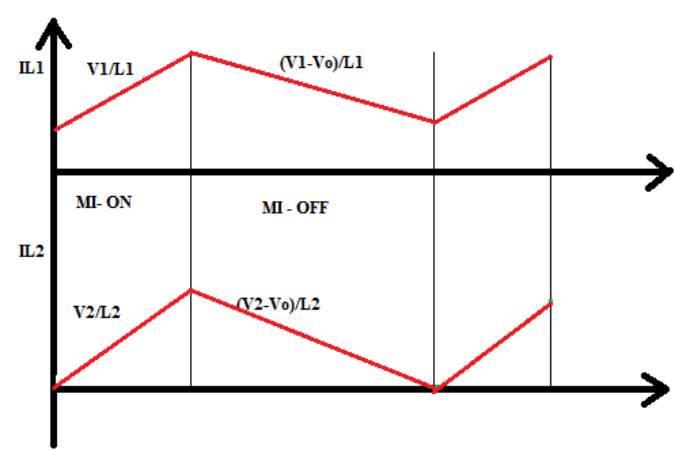

Fig. 10. Inductor current waveforms $\mathrm{IL}_{1}$ andIL 2

\section{MASTER SOURCE CONTROL}

As DC bus is a small residential supply system which uses DC voltage based power distribution to various domestic loads the major supply sources used will be renewable energy sources which are interfaced to MISC converter. The source with highest power rating will be designated as the master source and all other low power sources will be used as slave sources.

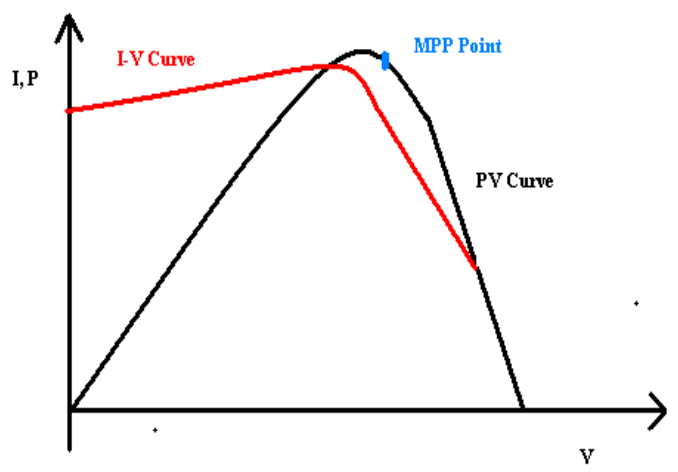

Fig. 11. Characteristics of solar panel

When MISC converter is used to supply power in DC bus the master source is selected as a solar panel which is modeled as a current source. The characteristics of solar panel are as shown in Fig. 11 for a particular solar radiation level. The point represented by Maximum Power Point (MPP) is the ideal point of operation of the solar panel. With the variation in radiation level MPP shifts and hence a controller is necessary to track the shifting point. The tracking of MPP point is done by the varying the duty cycle of MISC converter. There are various methods of tracking MPP available in literature. The tracking of MPP is done with the help of Perturb \& Observe ( $\mathrm{P} \& \mathrm{O})$ algorithm. The MPP point is calculated using $\mathrm{P} \& \mathrm{O}$ algorithm by observing the change in power for the variation of duty cycle [7]. The direction of change of duty cycle is based on the direction of change in power. The slave sources that can be connected to MISC are as shown in Fig. 3. For Mode I operation a low power fuel cell can be interfaced as slave source. Depending on the terminal voltage sub modes I (A) 
or I(B) exists as the operating mode. For Mode II operation a lower power solar panel is interfaced as the slave source to the converter. If the panel is selected such than the MPP of slave source matches the MPP of master source in normal radiation level we can extract maximum power from both the panels with a single control switch. The input inductor and capacitor value is properly designed so as to prevent high ripple operation of the converter.

\section{EXPERIMENTAL RESULTS}

An experimental prototype and hardware is developed to test Mode I to Mode IV operation of MISC as shown in Fig. 12 and Fig. 13 respectively. The master source used is a solar panel. MPPT is implemented using a digital controller. A second voltage source or a full cell is used as the slave source depending on the mode of operation under test. The primary solar panel rated $34 \mathrm{WNoc}=21 \mathrm{~V}$ and Isc $=2$.IA is used. perturb \& observe algorithm is implemented on a PIC microcontroller during testing. The master source is a solar panel under MPP operation giving a terminal voltage VI $=14 \mathrm{~V}$ at MPP operating point and the dc source used has a terminal voltage of $\mathrm{V} 2=10 \mathrm{~V}$. As explained in Section V under Mode I operation the current through slave source operates in discontinuous current mode. The discontinuous current mode operation of slave source provides the higher gain requirement, when two voltage sources are interfaced to MISC converter. The current IL1 passing through master source inductor.

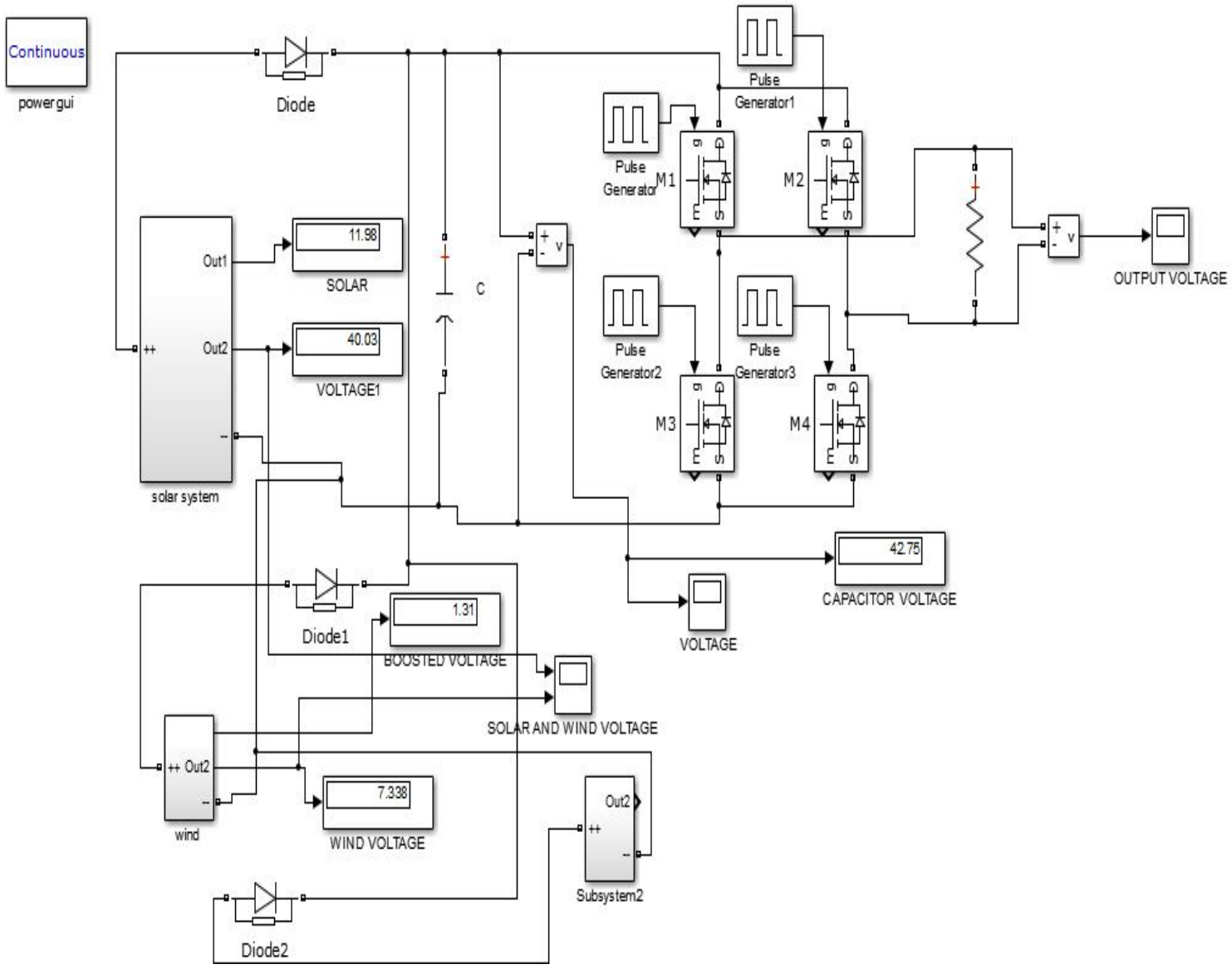

Fig. 12. The experimental prototype Model 


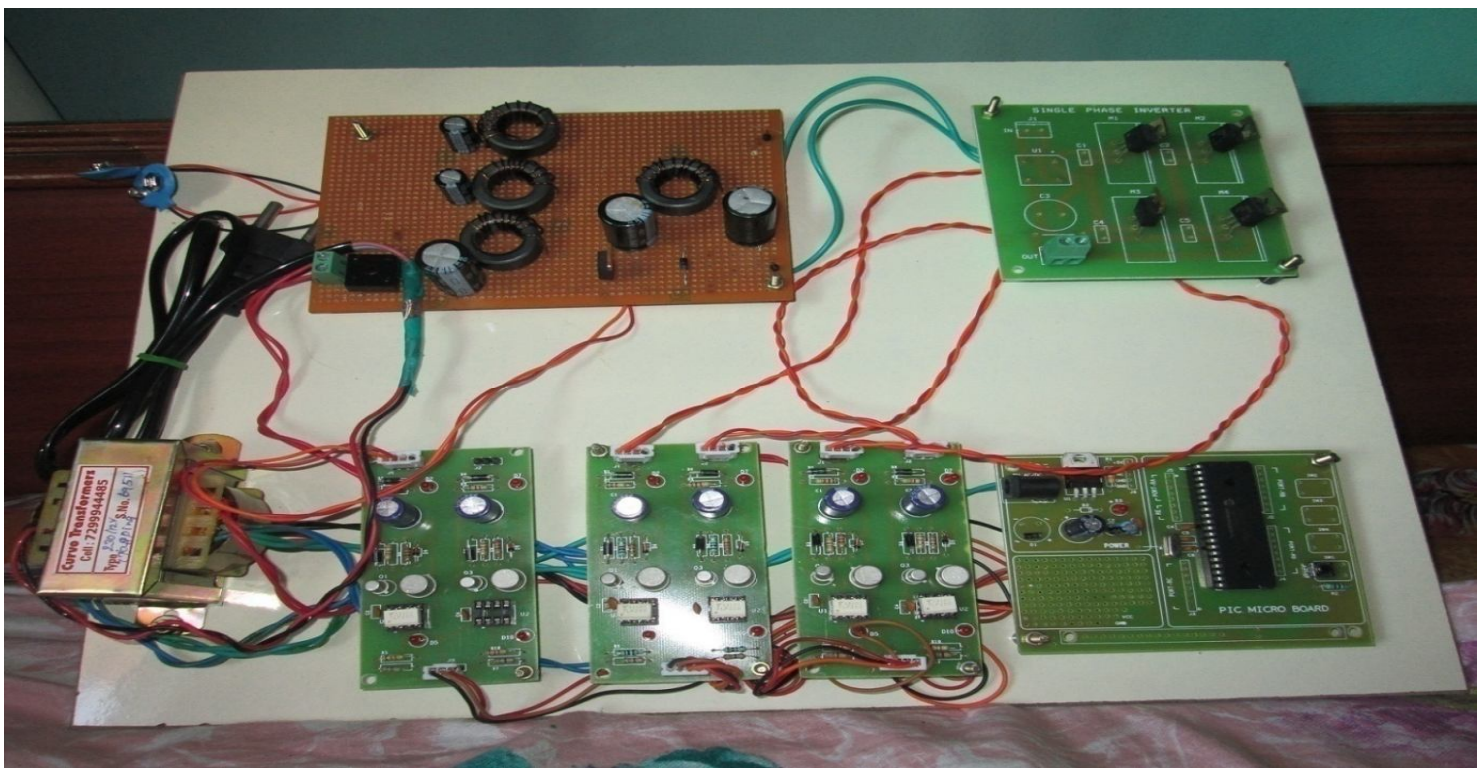

Fig. 13. The experimental hardware Model

Table. II. Components ratings

\begin{tabular}{|c|c|l|}
\hline \multirow{4}{*}{ MISC } & \multicolumn{2}{|c|}{ Components Specification } \\
\cline { 2 - 3 } & Parameters & Ratings \\
\cline { 2 - 3 } Converter & L1 & $1.40 \mathrm{mH}$ \\
\cline { 2 - 3 } & L2 & $600 \mu \mathrm{H}$ \\
\cline { 2 - 3 } & Cin1 Cin2 & $850 \mu \mathrm{F}$ \\
\cline { 2 - 3 } & Co & $38 \mu \mathrm{F}$ \\
\cline { 2 - 3 } & F $_{\text {switching }}$ & $10 \mathrm{kHZ}$ \\
\hline
\end{tabular}

Under Mode II operation If the inductor and capacitor values are properly selected it results is normal operation mode which is proved experimentally in Fig. 14 (a) and Fig. 14 (b). Both the inductor currents are in continuous current mode and maximum power is drawn from the master source which is under MPP operating point. The slave panel supplies the power that can be extracted at the particular point. If the inductor value used is very low which results in high ripple current, a high input capacitor has to be used to supply the required ripple. If the selection of capacitor value is not proper it results in high ripple mode of operation which is as seen in Fig. 15 (a) and Fig. 15 (b).

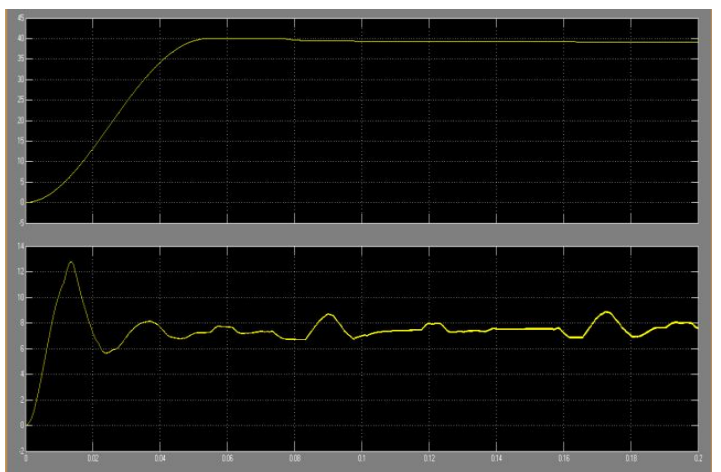

Fig.14(a).Master source under MPP operation.
The current IL2 passing through slave source has a negative portion which indicates the flow of current through inductor in opposite direction which is facilitated by the presence of input capacitor

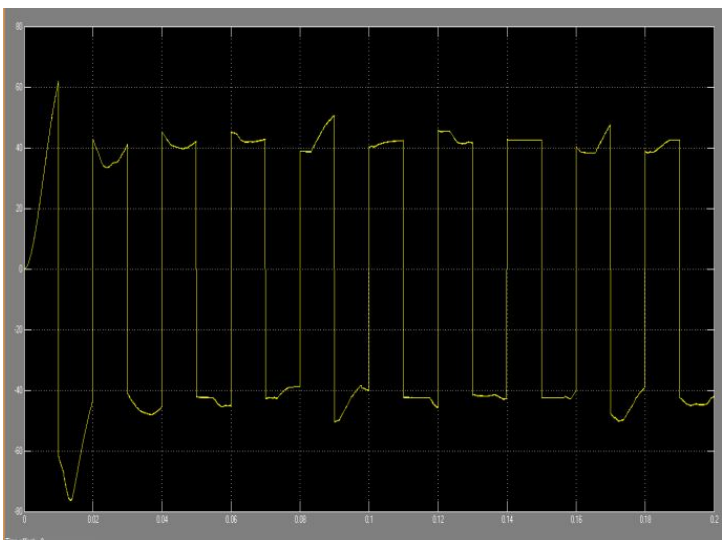

Fig. 14(b). Master source waveforms

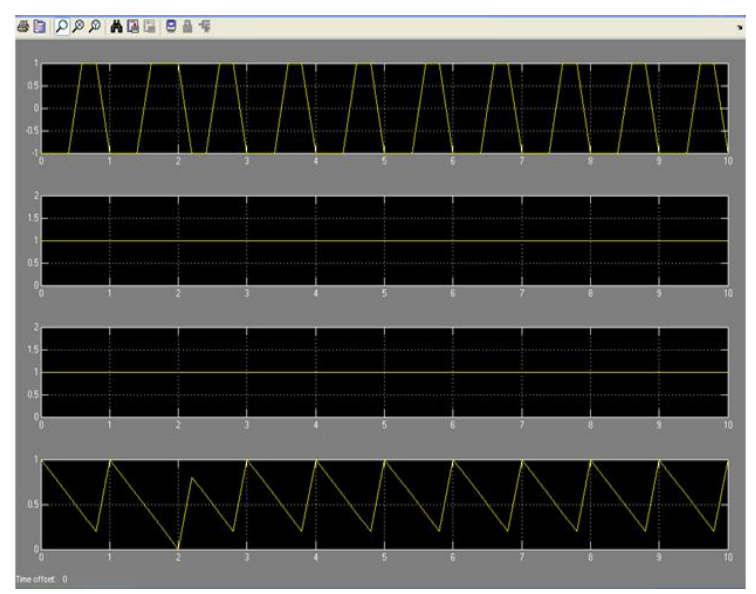

Fig.15(a) Master source waveforms 


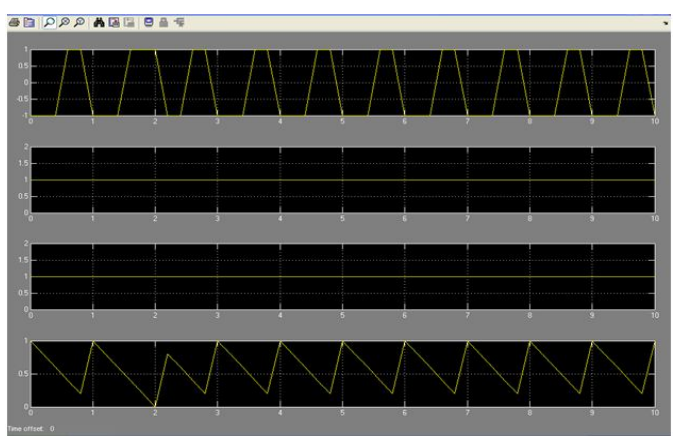

Fig. 15(b) Slave current source waveforms.

\section{CONCLUSION}

This paper proposed a Multi-Input-Single Control (MISC) converter. It accepts multiple inputs and boosts the voltage to distributing using a single control. A fixed duty cycle based on the highest power source (Master source) characteristics is used to control the circuit. The entire smaller sources act as slave and supply the power that can be extracted from it. Depending upon the interfaced source characteristics different modes of operations are possible. The modes operation is explained and the concept is experimentally validated using a prototype and hardware for different operating scenarios with a solar panel as a master source.

\section{REFERENCES}

[1] D.Dong, I.Cvetkovic, D.Boroyevich, W.Zhang, R.Wang, P.Mattavelli, "Grid-Interface Bidirectional Converter for Residential DC Distribution Systems-Part One: High-Density TwoStage Topology", IEEE Trans. Power Electron., Vol. : 28, no. 4, pp. 1655 - 1666, April 2013.

[2] Arun Sankar U, Soumya Shubhra Nag, Santanu K. Mishra "A Multi-Input Single-Control (MISC) Battery Charger for DC N anogrids978-1-47990482-2/13/2013 IEEE.

[3] R.Adda, O.Ray, S.K.Mishra, A.Joshi, "Synchronous-Reference-FrameBased Control of Switched Boost Inverter for Standalone DC Nanogrid Applications ", IEEE Trans. Power Electron., vol. 28, no. 3, pp. 1219 - 1233, Mar. 2013.

[4] Yasir Arafat, Mohammad Amin, "Feasibility study of low voltage DC house and compatible home appliance design".

[5] R.Adda, O.Ray, S.K.Mishra, A. Joshi, "Implementation and Control of Switched Boost Inverter for DC Nanogrid Applications," in Proc. IEEE Energy Conversion Congress and Exposition (ECCE) 2012, Raleigh, NC, Sept. 2012. pp. 38113818 .

[6] R.Adda, O.Ray, S.K.Mishra, A. Joshi, "DSP based PWM control of Switched Boost Inverter for DC Nanogrid applications," in Proc. 381h Annual
Conference of Industrial Electronics Society (I ECON) 2012, Montreal,

Canada, Oct. 2012, pp. 5285-5290.

[7] X.Li, A.Bhat, "Multi-Cell Operation of a HighFrequency Isolated DC/AC Converter for GridConnected Wind Generation Applications", Proc. of IEEE Int. Con! On Industrial and Information Systems (ICIIS), Dec. 2009, pp. 169 - 174.

[8] Gab-Su Seo, Jongbok Baek, Chul Woo Bak, Hyunsu Bae, Bohyung Cho, "Power Consumption Pattern Analysis of Home Appliances for DCbased Green Smart Home" Engineering Research Institute, Seoul National University Gwanangno 599, Kwanak-ku Seoul 151-744, KOREA.

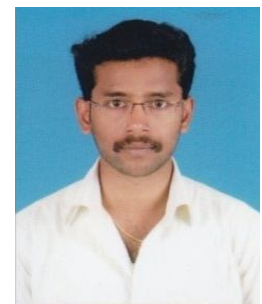

KARUPPIAH.M received the $\mathrm{BE}$ - Instrumentation and control engineering from Arulmigu kalasalingam college of engineering and $\mathrm{ME}$ Power electronics and drive from PSNA college of engineering and technology,

both the institute are under Anna university, Chennai, Tamilnadu. In the year of 2010-2011 he was worked as a production engineer at SNS industries in Bangalore, Karanataka. At present he is an Assistant professor in the department of electrical and electronics engineering at Vel tech engineering college in Avadi, Chennai, Tamilnadu.

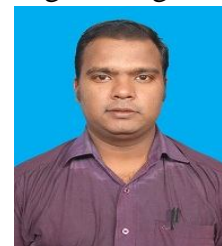

K.KARTHIKUMAR-received BE electrical and electronics engineering from Mookambigai college of engineering, keeranur, pudukottai, Tamilnadu and ME power system engineering from

college of engineering guindy Anna University Chennai ,Tamilnadu. He is currently working as a assistant professor in vel tech engineering college, Chennai, Tamilnadu. And doing research in college of engineering guindy anna university, Chennai, Tamilnadu. His area research interest is distributed generation and power system protection.

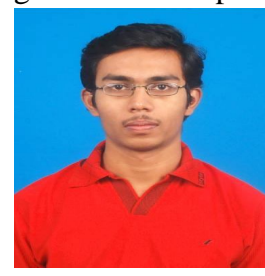

A.ARUNBALAJ-received B.E electrical and electronics engineering from I.F.E.T college of college, villupuram, Tamilnadu and M.E Power system engineering from college of engineering Guindy Anna University, Chennai, Tamilnadu.

$\mathrm{He}$ is currently working as an Assistant Professor in Vel tech engineering college, Chennai. Tamilnadu. 